\title{
Uma Análise das Diferenças em Termos da Cultura a Partir do Projeto de Substituição da IAS 39: Financial Instruments - Recognition and Measurement
}

\section{Resumo}

A cultura contabilística de cada país é frequentemente encarada como um obstáculo à plena harmonização contabilística. Este trabalho propõe-se a analisar as diferenças em termos da cultura a partir da participação dos respondentes nos processos de emissão/alteração de normas do International Accounting Standard Board (Iasb). Para o efeito, foram analisadas as comment letters enviadas ao Iasb no contexto da primeira parte da primeira fase do projeto de substituição da International Accounting Standard (IAS) 39: Financial Instruments - Recognition and Measurement pela International Financial Reporting Standard (IFRS) 9. Os países respondentes foram identificados em função da classificação proposta por Gray (1988), sendo posteriormente os dados recolhidos submetidos ao teste não paramétrico do quiquadrado. Os resultados deste estudo evidenciam a existência de diferenças em termos da cultura nas respostas obtidas dos países, particularmente no contexto do valor contabilístico do conservadorismo, não se identificando evidências de tais diferenças para os valores do secretismo, do profissionalismo e da uniformidade. Conclui-se, assim, que os países classificados como conservadores têm preferência por práticas de mensuração mais conservadoras, baseadas, designadamente, no custo ou no custo amortizado, em detrimento de critérios de mensuração baseados no justo valor. Pretende-se que os resultados obtidos neste estudo prestem o suporte necessário à tomada de decisões por parte dos organismos emissores de normas internacionais, bem como pelos responsáveis nacionais pela subscrição das referidas normas.

Palavras-Chave: Cultura, Harmonização, Normas Internacionais de Contabilidade, Sistemas Contabilísticos.

\section{Cláudia Daniela Ferreira da Mota Carvalho} Mestrado no Instituto Superior de Contabilidade e Administração de Lisboa e Técnica de Contabilidade EP - Estradas de Portugal. Contato: Praça da Portagem, $3^{\circ} \mathrm{D}$. Cidade Almada. Portugal. CEP.: 2809-013.

E-mail: carvalho@iscal.ipl.pt

Fábio Henrique Ferreira de Albuquerque

Doutorado na Universidade de Extremadura e Professor Adjunto no Instituto Superior de Contabilidade e Administração de Lisboa.

Contato: Av. Miguel Bombarda, n. 20.

Lisboa. Portugal. CEP.: 1150-020.

E-mail: fhalbuquerque@iscal.ipl.pt

\section{Joaquín Texeira Quirós}

Doutorado na Universidade de Extremadura e Professor Coordenador na Universidade Autónoma de Lisboa. Contato: Rua de Santa Marta, n. ${ }^{0} 56$. Lisboa. Portugal. CEP.: 1169-023.

E-mail: jquiros@ual.pt

\section{Maria do Rosário}

Fernandes Justino

Doutorado na Universidade de Extremadura e Professor Adjunto no Instituto Superior de Contabilidade e Administração de Lisboa. Contato: Av. Miguel Bombarda, n. 20. Lisboa. Portugal. CEP.: 1150-020.

E-mail: mrjustino@iscal.ipl.pt 


\section{Introdução}

Nos últimos anos, tem-se assistido, como consequência da globalização, à crescente liberdade de circulação de pessoas e bens, redes de transporte a nível internacional e interdependência comercial entre os continentes. A globalização, associada à complexidade das transações comerciais entre as empresas e à concentração de negócios em um ambiente de concorrência internacional, levam à procura de fundos junto de investidores diversificados (Alves \& Antunes, 2010). Nesse contexto, a informação financeira assume, particularmente nos mercados de capitais, um papel relevante como base para a tomada de decisão por parte dos utilizadores. Assim, a internacionalização das empresas, por um lado, e a necessidade de novos investidores, por outro, vêm realçar a importância da qualidade e comparabilidade da informação financeira, de forma a minimizar as diferenças nas práticas contabilísticas entre os diversos países.

Um dos principais objetivos da harmonização contabilística é alcançar a comparabilidade entre o relato financeiro publicado pelos países integrantes dos diversos sistemas contabilísticos. No processo de harmonização contabilística, destaca-se o trabalho desenvolvido pelo International Standards Board (Iasb), organismo emissor de normas contabilísticas de alta qualidade aceitas em quase todo o mundo.

A emissão do Regulamento Europeu n. ${ }^{\circ}$ 1.606/2002, do Parlamento Europeu e do Conselho, de 19 de julho, que obrigou as contas consolidadas das empresas com valores mobiliários admitidos à negociação em mercado regulamentado da União Europeia (UE) a serem preparadas de acordo com as normas internacionais de contabilidade emitidas pelo Iasb, foi um importante passo no movimento de harmonização contabilística no continente europeu.

Existem, no entanto, obstáculos à implementação de uma adequada harmonização em todo o mundo, derivada das diferenças nos sistemas contabilísticos, da nacionalidade e do idioma dos países adotantes, como afirmam Elnathan e Krlich (1992).

Diversos investigadores analisaram as principais causas que estão na base das diferentes práticas e, consequentemente, dos diferentes sistemas contabilísticos (Baydon \& Willett, 1995; Doupnik \& Salter, 1995; Gray, 1988; Nobes, 1998), incluindo-se, entre outros, os fatores relacionados com o sistema legal, o sistema fiscal, a cultura e o sistema econômico.

Entre os referidos fatores, o que tem sido alvo de maior atenção por parte dos estudiosos é a cultura, identificando-se uma vasta literatura a este respeito (e.g. Baydoun \& Willet, 1995; Chanchani \& Willett, 2004; Ding, Jeanjean \& Stolowy, 2005; Doupnik \& Riccio, 2006; Finch, 2006; Gray, 1988; Hope, 2003; Hope, Kang, Thomas \& Yoo, 2008; Jaggi \& Low, 2000; Perera, Cummings \& Chua, 2012; Tsakumis, 2007).

O processo de emissão de normas por parte do Iasb é suscetível de ser influenciado pela opinião dos interessados, uma vez que o Iasb coloca à disposição dos mesmos diversas formas de participação (e.g. reuniões e comment letters). Autores, como Carmo, Ribeiro \& Carvalho (2011) e Jorissen, Lybaert e Van de Poel (2006), defendem que os participantes nesse processo têm interesses distintos (muitas vezes contrários), fato que leva a que as respostas obtidas variem.

A crescente harmonização contabilística, tendencialmente, ditaria o fim da influência da cultura no julgamento profissional dos preparadores da informação financeira, tendo em conta os seus objetivos. Contudo, a introdução das normas no contexto nacional, sem considerar aspetos culturais e institucionais que cercam os países, pode conduzir a convergência contabilística a uma simples questão de formalidade (Carmo, et al., 2011).

O presente trabalho propõe-se a investigar as diferenças em termos da cultura, tendo por base os valores culturais propostos por Gray (1988), a partir da participação dos países respondentes nos processos de emissão/alteração de normas do International Accounting Standard Board. Para o efeito, serão analisadas as questões postas à discussão por parte do Iasb aos preparadores e utilizadores da informação financeira e organismos normalizadores relativamente à primeira parte da primeira fase do projeto de substituição da International Accounting Standard (IAS) 39 - Instrumentos Financeiros: Classificação e mensuração pela International Financial Reporting Standard (IFRS) 9. 
O estudo das diferenças internacionais no âmbito da Contabilidade em torno da cultura é importante para os países e organismos envolvidos no processo de harmonização contabilística internacional, na medida em que permite perceber quais os principais obstáculos a enfrentar para atingir a plena harmonização.

Mesmo em uma fase avançada do processo de harmonização, espera-se que este e outros estudos neste campo de investigação continuem a prestar o suporte necessário à tomada de decisões por parte dos organismos emissores de normas internacionais, bem como pelos responsáveis nacionais pela subscrição das referidas normas.

\section{Fundamentação Teórica}

O principal objetivo da harmonização contabilística é, conforme anteriormente referido, eliminar as diferenças nos sistemas contabilísticos, de forma que as demonstrações financeiras de empresas de diferentes países se tornem comparáveis, sendo o Ias $b$ apontado como o principal responsável pela difusão da harmonização contabilística internacional ao emitir normas internacionais de elevada qualidade. A aplicação das normas internacionais de contabilidade resulta de um conjunto diverso de forças, dentre as quais se destacam a pressão exercida pelos segmentos profissionais, as decisões políticas nacionais e internacionais e o envolvimento dos diversos setores que atuam no mercado. As práticas contabilísticas são diferentes de país para país o que origina normalizações diferentes, refletindo o ambiente social, econômico, cultural, legal e político em que se inserem, sendo, por isso, o resultado da interação de diversos fatores ambientais. Assim, cada país tem um sistema contabilístico adequado à sua realidade (Carmo, et al., 2011).

Nobes (1998) considera que o sistema financeiro e a herança colonial são os principais influenciadores dos sistemas contabilísticos. Assim, distingue dois sistemas contabilísticos, o primeiro correspondente aos chamados países do eixo anglo-saxónico (Reino Unido, Estados Unidos da América, Irlanda) e outro correspondente aos países europeus continentais (França, Alemanha, Itália). Os países anglo-saxônicos caracterizam-se pelas práticas contabilísticas menos conservadoras, com menor influência da fiscalidade e um mercado de capitais muito desenvolvido, que representa a principal fonte de financiamento das empresas, em que os principais utilizadores da informação financeira são os investidores. Por outro lado, os países europeus continentais possuem uma contabilidade mais conservadora, práticas contabilísticas mais aderentes às regras fiscais e um sistema financeiro cujo capital é fornecido principalmente pelo sistema bancário, no qual os principais utilizadores da informação financeira são os credores, a autoridade tributária e os investidores.

De acordo com a classificação proposta por Nobes (1998), as IAS/IFRS e os princípios contabilísticos geralmente aceitos nos Estados Unidos da América (EUA) têm origem anglo-saxônica. A herança colonial pode afetar as práticas contabilísticas de um país na medida em que países menores, menos desenvolvidos, ou ex-colônias são, muitas vezes, alvo de fortes influências externas, tornando-se culturalmente dominados. Esses países usam normalmente o sistema contabilístico adotado no país influenciador, mesmo que inadequado às suas necessidades (Nobes, 1998).

Dentre os diversos estudos relacionados com as causas das diferenças contabilísticas entre os sistemas, destaca-se o trabalho desenvolvido por Gray (1988), que, partindo do modelo teórico de Hofstede (1980), desenvolveu um estudo que relaciona a cultura com as práticas de contabilidade. Hofstede (1980) teve como objetivo identificar os elementos estruturais da cultura que afetam mais fortemente os comportamentos em situações de trabalho em organizações e instituições (Gray, 1988). Para isso, o autor analisou questionários prexistentes (realizados entre 1967 e 1973) sobre a atitude dos trabalhadores, conduzidos a uma amostra de mais de 116.000 funcionários da IBM em 39 países. Por meio desses questionários, e a partir de técnicas estatísticas, foram definidas quatro dimensões de valores sociais em que cada país pode estar posicionado, nomeadamente (Hofstede, 1980): 
1. Individualismo versus coletivismo - a questão fundamental desa dimensão é perceber qual o grau de interdependência que uma sociedade mantém entre os indivíduos;

2. Grande versus pequena distância do poder - nessa dimensão, a questão fundamental é perceber como uma sociedade lida com as desigualdades sociais quando estas ocorrem;

3. Forte versus fraca aversão ao risco - a questão dessa dimensão é perceber como uma sociedade reage perante a incerteza;

4. Masculinidade versus feminilidade - nessa dimensão, questiona-se como uma sociedade associa os papéis sociais aos diferentes gêneros.

Gray (1988), por sua vez, propôs uma relação entre as dimensões culturais de Hofstede (1980) e os diferentes sistemas contabilísticos dos países, a partir da identificação dos valores contabilísticos que possibilitam a classificação contabilística de um país com base na sua cultura. A relação entre a cultura social e a subcultura da contabilidade identifica-se a partir da associação entre os valores sociais e os valores contabilísticos, tendo por base a análise da forma como estes últimos valores influenciam o desenvolvimento dos sistemas contabilísticos. A Figura 1 representa um modelo desse processo.

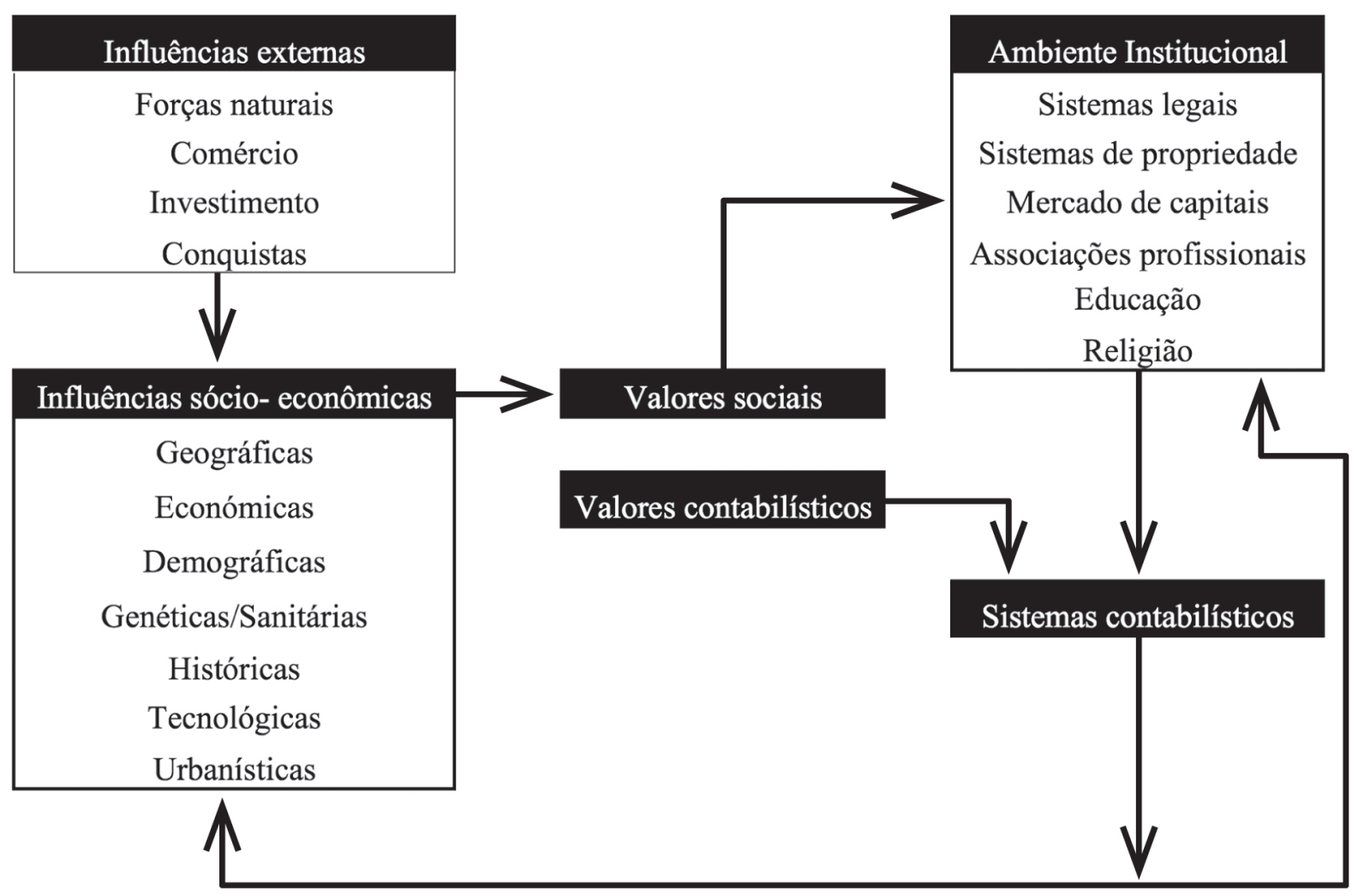

Figura 1. Relação entre o modelo de Hofstede (1980) e o modelo de Gray (1988)

Fonte: Radebaugh e Gray (1996)

Neste modelo, os valores sociais são determinados por elementos específicos de cada país (influências internas), tais como a geografia, a economia, a demografia, a genética, a história, a tecnologia e o urbanismo, que sofrem, por sua vez, influências externas, como o comércio internacional e o investimento estrangeiro. Os valores da sociedade, que estão na base dos valores contabilísticos, têm consequências institucionais sob a forma dos sistemas legais, política, natureza dos mercados de capitais, associações profissionais, educação, religião e influenciam os valores contabilísticos. As consequências institucionais reforçam as influências internas que, em conjunto com os valores contabilísticos, determinam a classificação dos países em torno dos sistemas contabilísticos. 
Gray (1988) identificou no seu estudo os seguintes valores contabilísticos:

1. Profissionalismo versus controle estatutário - diz respeito à preferência pelo exercício de um julgamento profissional individual livre em oposição ao cumprimento de requisitos legais e do controle estatutário;

2. Uniformidade versus flexibilidade - relaciona-se com a preferência pela aplicação de práticas uniformes de contabilidade entre empresas e pelo uso consistente dessas práticas ao longo dos anos em oposição à flexibilidade, de acordo com as circunstâncias de cada empresa;

3. Conservadorismo versus otimismo - identifica-se com a preferência por uma mensuração mais prudente de forma a lidar com a incerteza de eventos futuros, em oposição a uma mensuração mais otimista e disposta a assumir riscos;

4. Secretismo versus transparência - encontra-se associado à preferência pela confidencialidade e à restrição de divulgação de informação do negócio apenas para quem está intimamente envolvido com a gestão e o financiamento empresarial, em oposição a uma abordagem mais transparente e aberta ao exterior.

A partir dos valores sociais identificados por Hostede (1980) e tendo por base os valores contabilísticos identificados em seu estudo, Gray (1988) desenvolveu quatro hipóteses de relacionamento entre os dois modelos:

H1: Quanto mais alta for a posição de um país em termos de individualismo e menor em termos de aversão ao risco e de distância do poder, maior a probabilidade de uma elevada classificação em termos de profissionalismo.

H2: Quanto mais alta for a posição de um país em termos de aversão ao risco e distância do poder e mais baixa em termos de individualismo, maior será a probabilidade de uma elevada classificação em termos de uniformidade.

H3: Quanto mais alta a posição de um país em termos de aversão ao risco e mais baixa em termos de individualismo e masculinidade, maior é a probabilidade de estarem melhor classificados em termos de conservadorismo.

H4: Quanto mais alta a posição de um país em termos de aversão ao risco e de distância do poder e mais baixa em termos de individualismo e masculinidade, maior será a probabilidade de uma elevada classificação em termos de secretismo.

A Tabela 1 ilustra a ligação entre o modelo de dimensões culturais de Hofstede (1980) e os valores contabilísticos de Gray (1988), indicando a existência de treze hipóteses de relacionamento entre as variáveis propostas por este autor.

Tabela 1

Hipóteses de relacionamento do modelo de Hofstede (1980) com o modelo de Gray (1988) ${ }^{1}$

\begin{tabular}{lcccc}
\hline Dimensões Culturais & Profissionalismo & Uniformidade & Conservadorismo & Secretismo \\
\hline Distância do poder & - & + & $?$ & $?$ \\
\hline Aversão ao risco & - & + & + & + \\
\hline Individualismo & + & - & - & - \\
\hline Masculinidade & $?$ & $?$ & - & - \\
\hline Fonte: Radebaugh e Gray (1996) & & & &
\end{tabular}

1 O símbolo “+” indica uma relação direta entre as variáveis relevantes; o símbolo “- “indica um relacionamento inverso. O ponto de interrogação indica uma natureza de relação indeterminada. 
Tendo formulado as hipóteses relativamente aos valores sociais e aos valores contabilísticos, Gray (1988) relacionou os valores contabilísticos com as práticas contabilísticas dos países (Baydoun \& Willett, 1995). Dessa forma, fez uma distinção entre a autoridade dos sistemas contabilísticos, ou seja, entre a medida em que a contabilidade é determinada pelos organismos nacionais, incluindo associações profissionais e as caraterísticas de mensuração e divulgação da informação. Para Gray (1988), os valores contabilísticos mais diretamente relacionados com os organismos nacionais, no âmbito dos sistemas contabilísticos, são o profissionalismo e a uniformidade, uma vez que estão relacionados com a capacidade de regulação e o grau de execução ou conformidade. Por seu turno, os valores contabilísticos associados à mensuração e ao grau de divulgação são o conservadorismo e o secretismo.

Tendo por base tais elementos, Gray (1988) identificou a posição de cada sistema contabilístico em termos dos valores contabilísticos. A Figura 2 apresenta a posição dos sistemas contabilísticos em termos de autoridade e profissionalismo.

É observável que, em relação à autoridade dos sistemas contabilísticos, a cultura dos países anglo-saxônicos contrasta com a cultura dos países germânicos e dos países latinos mais desenvolvidos relativamente ao valor contabilístico da uniformidade, sendo os países anglo-saxônicos mais flexíveis. Relativamente ao valor contabilístico do profissionalismo, a cultura dos países anglo-saxônicos diferencia-se da cultura dos países latinos menos desenvolvidos, bem como dos países asiáticos, sendo a contabilidade destes últimos mais influenciada pelo controle estatutário.

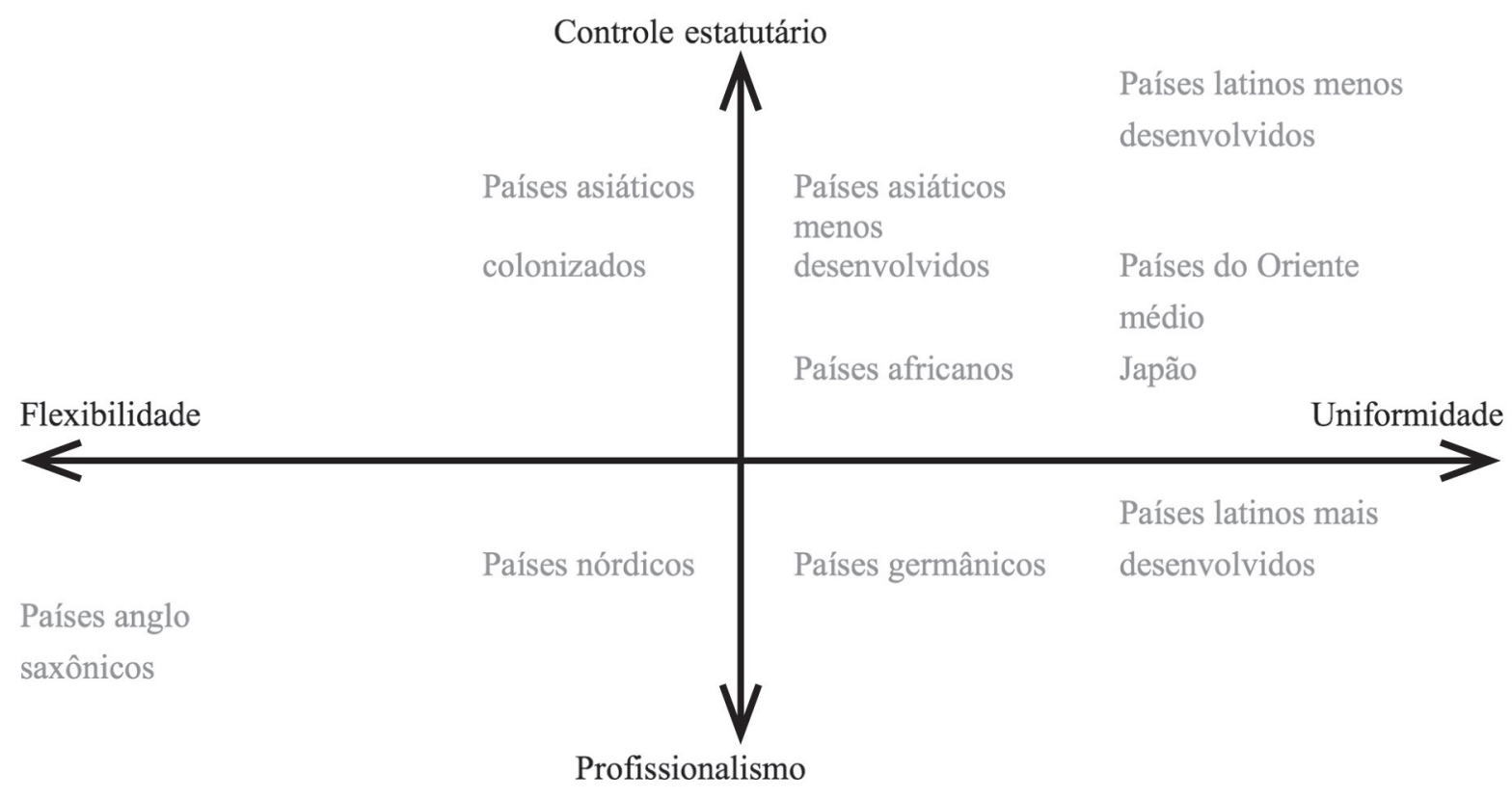

Figura 2. Sistemas contabilísticos: Autoridade e conformidade

Fonte: Gray (1988)

Note-se que, conforme Gray (1988), Portugal enquadra-se no conjunto dos países latinos menos desenvolvidos, sendo por isso identificado como um país com levados níveis de uniformidade, controle estatutário, conservadorismo e secretismo. 
A Figura 3 apresenta a posição dos sistemas contabilísticos em termos de secretismo e conservadorismo.

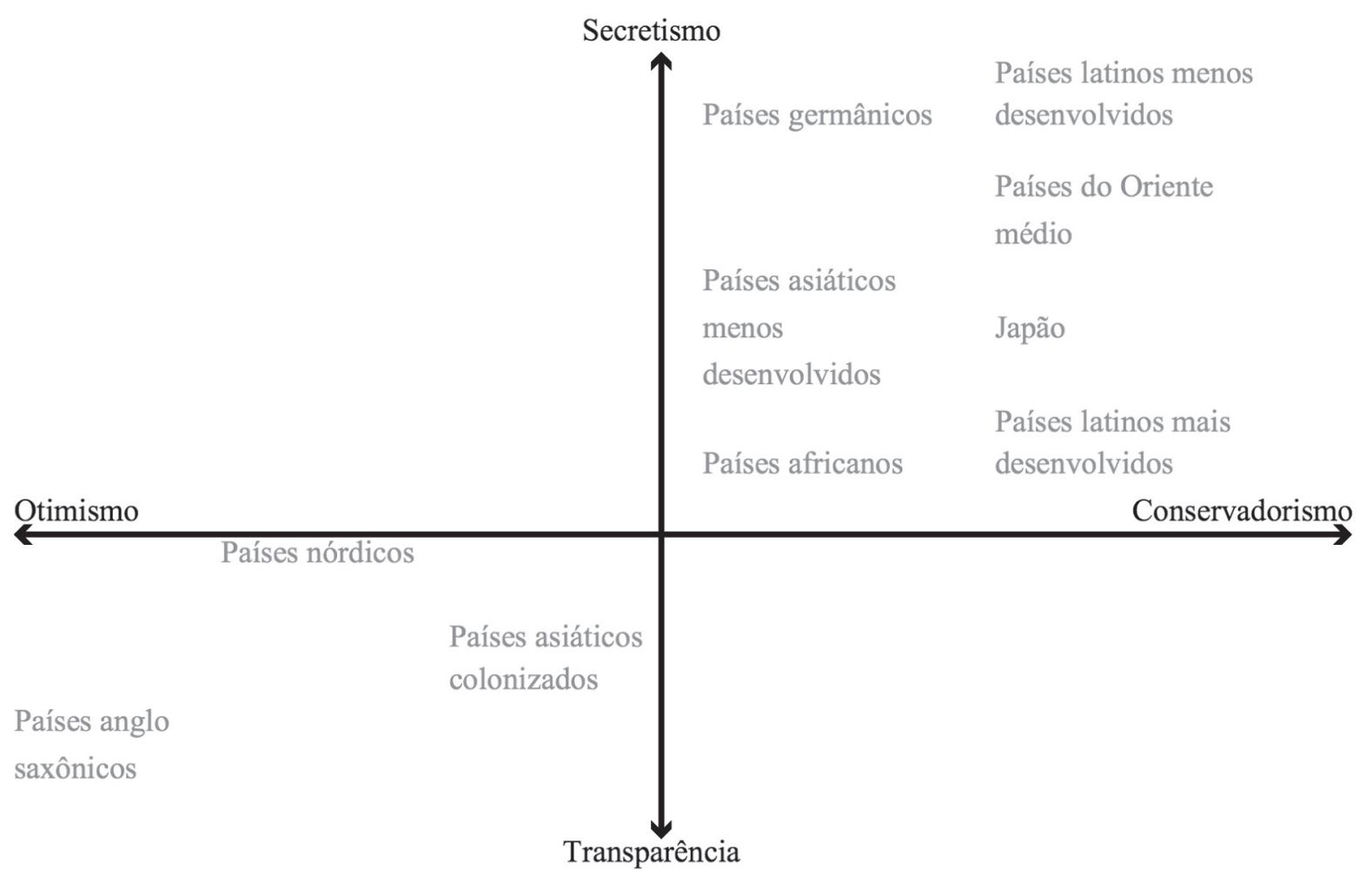

Figura 3. Sistemas contabilísticos: Mensuração e divulgação

Fonte: Gray (1988)

Em relação à mensuração e à divulgação, Gray (1988) identifica que os países colonizados da Ásia estão mais próximos da cultura anglo-saxônica e nórdica, com mensurações mais otimistas e divulgações mais transparentes, em contraste com os países de cultura germânica, latina, africana e asiática menos desenvolvida, que apresentam mensurações mais conservadoras e mais secretismo nas divulgações.

Apesar de introduzir uma nova abordagem relativamente à relação entre os sistemas contabilísticos e os valores sociais, Gray (1988) não testou as hipóteses por si formalizadas. O seu trabalho serviu no entanto de referência a vários estudos posteriores (Baydoun \& Willett, 1995; Chanchani \& Willett, 2004; Hope, 2003; Tsakumis, 2007).

Com o objetivo de verificar se o sistema contabilístico francês impunha práticas de mensuração e divulgação irrelevantes para os utilizadores da informação financeira do Líbano, Baydoun e Willett (1995) relacionaram os valores contabilísticos de Gray (1980) no contexto do sistema contabilístico do país, tendo em conta a posição cultural do Líbano proposta por Hofstesde (1980). Comparando os valores culturais de Hofstede (1980), entre o Líbano e a França, os autores concluem que no Líbano a aversão à incerteza é baixa e a masculinidade alta se comparadas com as da França; a distância do poder é baixa relativamente à França; e quanto ao individualismo são similares, o que significa que, utilizando as hipóteses propostas por Gray (1988), a contabilidade no Líbano deveria ser menos uniforme, menos conservadora e menos secreta relativamente à contabilidade na França. Tal como Gray (1980), no entanto, Baydoun e Willett (1995) não operacionalizaram as suas hipóteses, sendo que o estudo empírico a este modelo foi realizado por Chanchani e Willett (2004). 
O estudo de Chanchani e Willett (2004) apresenta os resultados de um questionário conduzido a utilizadores e preparadores da informação financeira da Nova Zelândia e da Índia. Nesse estudo, os autores encontraram um suporte razoável para os valores da uniformidade, profissionalismo e secretismo, sendo que, para o valor do conservadorismo, encontraram menos suporte e a possibilidade de existência de dois valores que podem estar relacionados com o conservadorismo; a orientação progressiva - tradicionalista, relacionada com questões técnicas de mensuração e divulgação; e a orientação ética, relacionada com questões como a justiça e honestidade (Chanchani \& Willett, 2004).

Hope (2003) investigou a relação entre a cultura e a origem legal e o nível de divulgação das empresas. Para o efeito, examinou os relatórios e as contas de empresas de trinta e nove países (em alguns testes, quarenta e dois países), concluindo que, em que pese a existência de outros fatores que influenciam o nível de divulgação, a cultura é um importante fator explicativo.

O trabalho de Tsakumis (2007) investiga a influência da cultura na interpretação e aplicação das regras contabilísticas nos diversos países, com especial ênfase nos valores contabilísticos do conservadorismo e do secretismo propostos por Gray (1988). Com base no referido objetivo, o autor selecionou a Grécia como representante do alto conservadorismo e secretismo, e os EUA selecionados como representantes de baixos níveis de conservadorismo e secretismo. Foram conduzidos inquéritos para analisar a influência da cultura nas decisões de reconhecimento e divulgação de ativos e passivos contingentes dos contabilistas gregos e americanos. No referido estudo, Tsakumis (2007) observa que, relativamente às decisões de reconhecimento, não foram encontradas diferenças significativas entre os dois países. No entanto, relativamente à divulgação, os resultados revelam que os contabilistas gregos são menos propensos que os americanos a divulgar nos anexos a existência de ativos ou passivos contingentes. Esses resultados levaram Tsakumis (2007) a concluir que as práticas de divulgação são mais influenciadas pela cultura do que as práticas de mensuração.

Em Portugal, a teoria da relevância cultural da Contabilidade proposta por Gray (1988) foi operacionalizada por Albuquerque e Almeida (2009), por meio da análise das respostas obtidas a partir de um questionário conduzido a uma amostra de Técnicos Oficiais de Contas portugueses. Recorde-se que, de acordo com o modelo de Gray (1988), Portugal enquadra-se no conjunto de países latinos menos desenvolvidos, apresentando elevados níveis de controle estatutário, uniformidade, secretismo e conservadorismo. Os resultados obtidos pelo estudo de Albuquerque e Almeida (2009) sugerem um razoável apoio à teoria de Gray (1988).

Existem diversos fatores ambientais que influenciam as práticas e, consequentemente, os sistemas contabilísticos, como a cultura, os sistemas legais, políticos, econômicos e financeiros. Dentre todos os fatores considerados influenciadores das práticas contabilísticas, o que tem sido alvo de maior atenção por parte dos investigadores é a cultura, existindo uma vasta literatura a este respeito (e.g. Abdolmohammadi e Sarens, 2009; Amat, Blake, Wraith e Oliveras, 2010; Baydoun e Willet, 1995; Chanchani e Willet, 2004; Ding, Jeanjean e Stolowy, 2005; Doupnik e Riccio, 2006; Finch, 2006; Gray, 1988; Hope, 2003; Hope, Kang, Thomas e Yoo, 2008; Jaggi e Low, 2000; Perera, Cummings e Chua, 2012; Tsakumis, 2007).

A importância da cultura na influência e explicação de comportamentos nos sistemas sociais tem sido reconhecida e explorada em uma vasta gama de áreas do conhecimento, principalmente em Antropologia, Sociologia e Psicologia (Gray, 1988).

O processo de normalização do Iasb permite a todos os interessados nesse processo a participação nas discussões públicas e emissão de opinião por meio de comment letters, podendo esses comentários ser influenciados por distintos fatores, como a envolvente cultural. Nesse sentido, autores, como MacArthur (1996), Jorissen, Lybaert e Van de Poel (2006) e Carmo et al. (2011), relacionam as respostas obtidas em formato de comment letter com diversos fatores explicativos, incluindo os valores culturais identificados por Gray (1988) e propostos para este estudo.

A Tabela 2 apresenta de forma resumida os fatores explicativos usados pelos autores anteriormente referidos na análise às respostas obtidas pelo Iasb por meio de comment letters às suas propostas de normas ou de alterações de normas: 
Tabela 2

Estudos anteriores que relacionam as respostas das comment letters com fatores explicativos

\begin{tabular}{ll}
\hline \multicolumn{1}{c}{ Estudos } & \multicolumn{1}{c}{ Fatores explicativos } \\
\hline \multirow{2}{*}{ MacArthur (1996) } & - Dimensões culturais de Hofstede (1980); \\
& - Valores contabilísticos de Gray (1988) \\
\hline & - Dimensões culturais de Hofstede (1980); \\
& - Custos de não cumprimento (contabilidade e fiscalidade); \\
Jorissen et al. (2006) & - Força das empresas de auditoria; \\
& - Interesses dos preparadores: dimensão e interesses das empresas; \\
& - Nível de informação financeira divulgada em revistas e artigos. \\
\hline Carmo et al. (2011) & - Classificação dos sistemas legais proposta por La Porta, Silanes, Shleifer e Vishny (1996). \\
\hline
\end{tabular}

Dentre os trabalhos anteriores, destaca-se o trabalho desenvolvido por MacArthur (1996), por estar mais relacionado com o objetivo do presente estudo e por investigar a influência dos fatores culturais nas respostas em formato de comment letters submetidas por 47 empresas de 9 países (Austrália, Canadá, França, Alemanha, Holanda, Reino Unido, África do Sul, Suíça, e EUA) ao International Accounting Standard Commité (Iasc) na sequência das alterações a 12 das mais importantes IAS propostas pela E32. A E32 propunha alterações relacionadas com a valorização e apresentação de inventários, alterações nas políticas contabilísticas, estimativas e erros, custos com investigação e desenvolvimento, contratos de construção, ativos fixos tangíveis, locações, reconhecimento de réditos, benefícios de empregados, alterações em taxas de câmbio, combinações de negócios, custos de empréstimos obtidos e investimentos.

O autor tentou estabelecer relações entre o país de origem das respostas e as dimensões culturais de Hofstede (1980) e os valores culturais de Gray (1988). Os resultados obtidos foram consistentes com a expectativa de que a cultura e a subcultura da contabilidade afetam as preferências contabilísticas dos profissionais da contabilidade das empresas respondentes. Relativamente às dimensões culturais, os resultados mostraram consistência para as dimensões da distância do poder e do individualismo, enquanto que, para a aversão à incerteza e masculinidade, as hipóteses apenas foram parcialmente suportadas. Para os valores da subcultura da contabilidade, foi encontrado um forte suporte para as empresas de origem nórdica e anglo-saxônica, enquanto que, para as empresas de origem germânica e latina desenvolvida, o suporte encontrado foi inferior, em particular, a presença de elevados níveis de uniformidade e de secretismo foram menos evidentes do que o esperado para essas duas últimas origens.

Ressalte-se que, além do referencial de Hofstede-Gray, outros modelos desenvolvidos no âmbito da cultura, como o modelo de Schwartz (1994) e posteriores desenvolvimentos propostos, têm sido largamente utilizados na explicação dos fenômenos sociais que afetam a Contabilidade, baseando-se, fundamentalmente, na utilização de índices de valores culturais para a classificação dos países. No entanto, em que pese a continuidade da aplicação de tais modelos, em particular, o modelo de dimensões culturais de Hofstede (1980), os modelos baseados em índices têm sido duramente criticados, merecendo tais resultados a devida prudência (Baskerville, 2003).

Nesse sentido, o modelo teórico de Gray (1988) com a aplicação proposta, designadamente, por MacArthur (1996), apresentam-se adequados aos objetivos propostos para este estudo, nomeadamente, na identificação das diferenças em termos da cultura por parte dos países respondentes das comment letters do Iasb. Para o efeito, serão analisadas as questões postas à discussão por parte do Iasb aos preparadores e utilizadores da informação financeira e organismos normalizadores relativamente à primeira parte da primeira fase do projeto de substituição da Internacional Accounting Standard (IAS) 39 - Instrumentos Financeiros: Classificação e mensuração pela International Financial Reporting Standard (IFRS) 9. A escolha deste tema prende-se com o fato de o tratamento contabilístico dos instrumentos financeiros ser considerado um tema complexo, que envolve problemáticas em que é possível identificar a influência de fatores 
como a cultura ou os interesses profissionais. Outro fato que esteve na base da referida escolha prende-se com o elevado índice de participação, tendo em conta o interesse que o tema desperta em diversas partes interessadas (preparadores, utilizadores da informação financeira e organismos normalizadores).

O próximo ponto apresenta as linhas metodológicas seguidas no desenvolvimento do estudo empírico proposto para este artigo.

\section{Metodologia}

O presente trabalho propõe-se a investigar as diferenças em termos da cultura, tendo por base os valores culturais propostos por Gray (1988), nomeadamente, o conservadorismo, o profissionalismo, a uniformidade e o secretismo, a partir da participação dos países respondentes nos processos de emissão/ alteração de normas do Iasb. A recolha dos dados para este estudo será feita por meio das comment letters de resposta à Exposure Draft - Instrumentos Financeiros Classificação e Mensuração, relativa ao projeto de substituição da IAS 39 pela IFRS 9 (primeira parte da primeira fase do projeto),

Assim, tendo em conta os objetivos específicos anteriormente definidos, e com base no referencial teórico divulgado na parte precedente, foi definida a seguinte hipótese $(\mathrm{H})$ geral:

H1: Verificam-se diferenças significativas em torno da cultura, consoante a classificação dos países em termos de valores contabilísticos proposta por Gray (1988).

Foram, no entanto, definidas hipóteses operacionais (H1.1 a H1.4) relacionadas com os valores contabilísticos do conservadorismo, profissionalismo, uniformidade e secretismo:

H1.1: Verificam-se diferenças significativas em termos de conservadorismo, consoante a classificação dos países proposta por Gray (1988).

H1.2: Verificam-se diferenças significativas em termos de profissionalismo, consoante a classificação dos países proposta por Gray (1988).

H1.3: Verificam-se diferenças significativas em termos de uniformidade, consoante a classificação dos países proposta por Gray (1988).

H1.4: Verificam-se diferenças significativas em termos de secretismo, consoante a classificação dos países proposta por Gray (1988).

A metodologia usada para analisar as comment letters foi a análise de conteúdo, por meio do qual foram obtidos os dados necessários à elaboração deste estudo. Esta análise é definida por Weber (1990), como citado em Yen, Hirst e Hopkins (2007) como um método de investigação que utiliza um conjunto de procedimentos com o objetivo de elaborar inferências a partir de determinado texto. Para o autor, a análise de conteúdo é particularmente útil, uma vez que permite transformar e codificar o texto de forma a que a pesquisa possa ser conduzida.

Para efeitos de realização do estudo proposto, as questões foram analisadas por meio da sua transformação em variáveis dicotômicas, pelo que a análise da resposta em "sim" (concordância) ou "não" (discordância) para cada uma das questões foi considerada suficiente para atingir os objetivos dos estudos propostos, à semelhança do proposto por Carmo et al. (2011).

As 15 questões apresentadas na exposure draft foram, em uma primeira fase, analisadas e fragmentadas, de forma a evitar a existência de múltiplas questões em um único ponto. Dessa fragmentação, resultaram 60 questões finais. Destas, apenas 20 foram alvo de análise, atendendo à possibilidade da sua codificação de uma forma o mais possível objetiva, consoante a concordância ou discordância em face da questão proposta. Assim, as questões que requeriam alternativas e explicações adicionais foram excluídas do âmbito deste trabalho. As referidas questões apresentam-se, assim, como as variáveis dependentes do estudo efetuado. A cada uma das questões em análise foi associado um valor contabilístico de Gray (1988). 
A Tabela 3 apresenta as questões analisadas, bem como a classificação da questão em termos dos valores contabilísticos propostos por Gray (1988), relevante para o estudo proposto. O sinal de “+” apresentado no Quadro 3 indica que a concordância com a questão proposta evidencia um maior enquadramento na definição subjacente ao valor contabilístico identificado, ao passo que o sinal de “-” evidencia a situação inversa.

Assim, e para efeitos da análise proposta para este estudo, os países respondentes serão identificados em termos do maior ou menor enquadramento na literatura para os valores contabilísticos (conservadorismo, profissionalismo, uniformidade e secretismo), tendo em conta a classificação do país do respondente (variável independente) proposta por Gray (1988) e de modo a validar a existência de diferenças entre as respostas obtidas para os distintos agrupamentos propostos para cada um dos referidos valores.

Tabela 3

Relação entre os valores contabilísticos e as questões da ED (2009)

\begin{tabular}{|c|c|c|}
\hline $\mathbf{N}^{\circ}$ & Questão & Valor Cultural \\
\hline 1.1 & $\begin{array}{l}\text { O custo amortizado fornece informação útil à tomada de decisão para um ativo ou passivo } \\
\text { financeiro que tenha características básicas de empréstimo e é gerido numa base de } \\
\text { rendimento contratual? }\end{array}$ & $(+)$ Conservadorismo \\
\hline 2.1 & $\begin{array}{l}\text { Acredita que a ED propõe orientações operacionais suficientes para perceber se um } \\
\text { instrumento tem características básicas de empréstimo e se é gerido numa base de } \\
\text { rendimento contratual? }\end{array}$ & (+) Profissionalismo \\
\hline 3.1 & $\begin{array}{l}\text { Acredita que outras condições podem ser mais apropriadas para identificar quais os ativos } \\
\text { ou passivos financeiros que devem ser mensurados ao custo amortizado? }\end{array}$ & (+) Conservadorismo \\
\hline 3.2 & $\begin{array}{l}\text { Se os ativos ou passivos financeiros que a ED mensura ao custo amortizado não respeitarem } \\
\text { as condições que propõe, pensa que estes ativos e passivos financeiros devem ser } \\
\text { mensurados ao justo valor? }\end{array}$ & (-) Conservadorismo \\
\hline 4.1 & $\begin{array}{l}\text { Concorda que os requisitos para mensuração de derivados embutidos num contrato híbrido } \\
\text { com um hospedeiro financeiro devem ser eliminados? }\end{array}$ & (-) Conservadorismo \\
\hline 4.2 & Concorda com a proposta das tranches? & (-) Conservadorismo \\
\hline 5.1 & $\begin{array}{l}\text { Concorda que as entidades devem continuar a permitir que alguns ativos e passivos } \\
\text { financeiros que deveriam ser mensurados ao custo amortizado sejam mensurados } \\
\text { ao justo valor através de resultados, se tal eliminar ou reduzir significativamente uma } \\
\text { incompatibilidade contabilística? }\end{array}$ & (+) Uniformidade \\
\hline 6.1 & Deverá a opção de justo valor ser permitida em outros casos? & (-) Conservadorismo \\
\hline 7.1 & Concorda que a reclassificação deve ser proibida? & (+) Uniformidade \\
\hline 8.1 & $\begin{array}{l}\text { Considera que se todos os investimentos em capital próprio forem mensurados ao justo } \\
\text { valor a informação financeira será mais útil? }\end{array}$ & (-) Conservadorismo \\
\hline 9.1 & Existem circunstâncias onde o benefício desta informação não supera o custo de a fornecer? & (+) Conservadorismo \\
\hline 10.1 & $\begin{array}{l}\text { Considera que apresentar as alterações ao justo valor de investimentos em instrumentos de } \\
\text { capital próprio em OCI pode melhorar o reporte financeiro? }\end{array}$ & $(+)$ Conservadorismo \\
\hline 10.2 & $\begin{array}{l}\text { Considera que apresentar os dividendos de investimentos em instrumentos de capital } \\
\text { próprio em } \mathrm{OCl} \text { pode melhorar o reporte financeiro? }\end{array}$ & (+) Conservadorismo \\
\hline 11.1 & $\begin{array}{l}\text { Concorda que deva ser permitido a uma entidade apresentar em OCl alterações ao justo } \\
\text { valor de qualquer investimento em instrumentos de capital próprio (exceto aqueles que são } \\
\text { detidos para negociação), apenas se optar por o fazer no reconhecimento inicial? }\end{array}$ & (+) Uniformidade \\
\hline 11.2 & $\begin{array}{l}\text { Devem as entidades apresentar alterações ao justo valor em capital próprio apenas nos } \\
\text { períodos em que os investimentos em instrumentos de capital próprio satisfaçam a } \\
\text { identificação proposta? }\end{array}$ & (+) Uniformidade \\
\hline 12.1 & $\begin{array}{l}\text { Concorda com as divulgações adicionais para as entidades que apliquem a IFRS antes da sua } \\
\text { data efetiva? }\end{array}$ & (-) Secretismo \\
\hline 13.1 & $\begin{array}{l}\text { Concorda com a aplicação retrospetiva das propostas e com as respetivas orientações de } \\
\text { transição? }\end{array}$ & (+) Uniformidade \\
\hline
\end{tabular}

Considera que a abordagem alternativa de registar ao custo amortizado apenas os ativos 14.1 financeiros que para além de satisfazerem as condições específicas da ED respeitem
também a definição de empréstimos e contas a receber da IAS 39,fornece informação mais

(-) Conservadorismo útil do que mensurar os ativos financeiros ao custo amortizado? 


\begin{tabular}{|c|c|c|}
\hline $\mathbf{N}^{\circ}$ & Questão & Valor Cultural \\
\hline 15.1 & $\begin{array}{l}\text { Considera que a variante possível de registar todos os instrumentos financeiros ao justo valor } \\
\text { fornece mais informações úteis para a tomada de decisão do que a abordagem alternativa } \\
\text { de mensurar ao custo amortizado os instrumentos financeiros que satisfaçam as condições } \\
\text { específicas da ED e respeitem a definição de empréstimos e contas a receber da IAS 39? }\end{array}$ & (-) Conservadorismo \\
\hline 15.2 & $\begin{array}{l}\text { Considera que a variante possível de registar todos os instrumentos financeiros ao justo } \\
\text { valor fornece mais informações úteis para a tomada de decisão do que a abordagem } \\
\text { proposta na ED de mensurar ao custo amortizado os instrumentos financeiros que } \\
\text { satisfaçam as condições específicas da ED? }\end{array}$ & (-) Conservadorismo \\
\hline
\end{tabular}

O secretismo representa a preferência pela restrição de divulgações acerca do negócio apenas para os terceiros que estão intimamente relacionados com a gestão, em oposição a divulgações mais transparentes, abertas e públicas (Gray, 1988).

Os países com elevados níveis de secretismo apresentam tendencialmente divulgações mais reduzidas, sendo favoráveis à restrição de divulgações. A opção por divulgações adicionais é, por outro lado, caraterística de sistemas contabilísticos mais transparentes.

Tendo em conta os pressupostos anteriores, o sentido de maior secretismo por parte dos respondentes será obtido por meio de uma preferência pela ausência de divulgações adicionais.

Assim, a questão 12.1 foi associada ao valor contabilístico do secretismo, em que a opção por divulgações adicionais é caraterística de sistemas contabilísticos mais transparentes, pelo que uma resposta afirmativa à questão, codificada com "1", significa um menor nível de secretismo, e uma resposta negativa, codificada com "0", significa um maior nível de secretismo.

O profissionalismo é a preferência pelo exercício de julgamento profissional em oposição a regras rígidas (Gray, 1988).

Qualquer evidência da necessidade de normas, de orientações específicas e precisas que não permitam o julgamento profissional é caraterística de países com baixos níveis de profissionalismo, pois quanto mais normalizado e regulamentado for um sistema contabilístico menos oportunidade haverá para o exercício de julgamento profissional (MacArthur, 1996).

Assim, tendo em conta os pressupostos anteriores, o sentido de maior profissionalismo por parte dos respondentes será obtido por meio de uma menor necessidade pelo estabelecimento de regras e orientações específicas estabelecidas na exposure draft em questão.

Em relação ao profissionalismo, a questão analisada foi a questão 2.1, uma vez que, quanto mais normalizado e regulamentado for um sistema contabilístico, menos oportunidades haverá de julgamento profissional. Logo, o sistema contabilístico terá um menor grau de profissionalismo. Assim, uma resposta afirmativa indica maiores níveis de profissionalismo (codificada com "1") e a resposta negativa indica menores níveis de profissionalismo (codificada com "0").

De acordo com Gray (1988), a uniformidade é a preferência por práticas contabilísticas semelhantes entre as empresas e pelo uso consistente dessas práticas ao longo do tempo.

Os sistemas contabilísticos uniformes apresentam tendencialmente uma reduzida quantidade de opções de reconhecimento e mensuração; não permitem a opção de diferentes práticas contabilísticas para distintas necessidades e defendem a aplicação retrospetiva de novas regras, em detrimento da aplicação prospetiva (MacArthur, 1996).

Assim, o sentido de maior uniformidade por parte dos respondentes será obtido por meio de uma maior preferência por práticas de mensuração semelhantes ao longo do tempo e entre distintas entidades; preferência pela aplicação retrospetiva de alterações a políticas contabilísticas; e preferência por práticas de mensuração que evitem inconsistências contabilísticas.

Relativamente à uniformidade, as questões relacionadas foram as 5.1, 7.1, 11.1, 11.2 e 13.1, uma vez que a preferência por práticas contabilísticas que reduzem incompatibilidades e semelhantes no tempo, tal como a proibição de reclassificações e a preferência por aplicação retrospetiva de novas práticas são 
caraterísticas de sistemas contabilísticos mais uniformes. Dessa forma, as respostas afirmativas indicam maiores índices de uniformidade (codificadas com “1”), e respostas negativas indicam menores índices de uniformidade (codificadas com "0").

Segundo Gray (1988), o conservadorismo é uma preferência por práticas de mensuração mais cautelosas, de forma a prevenir a incerteza de eventos futuros.

Autores como Gaver e Pottier (2005), Göx e Wagenhofer (2009) e Wang (2012) consideram que a mensuração ao justo valor contraria, em regra, o princípio do Conservadorismo e que a mensuração ao custo amortizado se apresenta mais conservadora do que ao justo valor.

Haller e Walton (2003), como citado em Carmo et al. (2011), consideram que os países mais conservadores apresentam uma maior tendência para o cálculo prudente do lucro tributável, limitando a distribuição deste por meio de reservas ocultas.

Assim, o sentido de maior conservadorismo por parte dos respondentes será obtido por intermédio de uma maior preferência pela mensuração ao custo amortizado, em detrimento do justo valor, com as alterações reconhecidas em capital próprio (other comprehensive income) em detrimento do reconhecimento diretamente em resultados.

As restantes questões encontram-se relacionadas com o conservadorismo, sendo a preferência por práticas de mensuração ao custo em detrimento de práticas de mensuração ao justo valor, bem como a preferência por efetuar alterações ao justo valor diretamente em capital próprio (other comprehensive income) são caraterísticas de sistemas contabilísticos mais conservadores. Relativamente às questões 1.1, 3.1, 9.1, 10.1 e 10.2, as respostas positivas indicam maiores níveis de conservadorismo e, por isso, foram codificadas com " 1 ", para as restantes questões, as respostas positivas indicam menores níveis de conservadorismo e, por isso, foram codificadas com " 0 ".

Não foi possível obter resposta para todas as questões apresentadas, sendo que algumas questões, como a 3.2, 11.1 e 11.2, apresentam uma elevada percentagem de não resposta (88\%, 55\% e 89\%, respetivamente), pelo que não foram consideradas para efeitos deste estudo.

Foram submetidas ao Iasb 246 comment letters relativas aos Instrumentos Financeiros, objeto de análise neste artigo, tendo-se identificado 10 situações em que o conteúdo delas se encontrava inacessível. Adicionalmente, um dos respondentes enviou duas comment letters; duas das cartas não traziam identificação do país de origem e dois dos respondentes apenas fizeram comentários, não respondendo a nenhuma das questões apresentadas em concreto. Assim, foi analisado um total de 231 cartas de resposta à primeira fase da minuta de exposição.

Das 231 cartas analisadas, referidas anteriormente, 30 foram enviadas por organismos internacionais e associações privadas e governamentais europeias, que foram classificadas em separado no grupo Internacional. No contexto deste estudo, as referidas cartas não foram consideradas por não se inserirem em nenhuma das classificações propostas por Gray (1988) e por não representarem nenhum país em particular, adotando-se um procedimento similar ao efetuado por Carmo et al. (2011).

A Tabela 4 apresenta o número de cartas recebidas, tendo em conta o país de origem e a classificação relevante no contexto deste estudo.

A classificação proposta para cada um dos países integrantes deste estudo encontra-se em linha com o estudo de Gray (1988).

Adicionalmente ao estudo de Gray (1988), a classificação dos países foi feita com base nos estudos de Hofstede (1980), Chow, Chau e Gray (1995) e MacArthur (1996), tendo em conta que os referidos estudos encontravam-se em linha com o primeiro, sendo ainda possível obter esclarecimentos adicionais acerca de algumas classificações propostas não evidenciadas diretamente naquele.

Da análise efetuada, tornou-se necessário excluir a única resposta proveniente de Luxemburgo, à semelhança do procedimento adotado por Roberts e Salter (1999), uma vez que não foi possível identificar a classificação do país nos referidos estudos. Após tal exclusão, a população final fixou-se em 200 cartas. 
Tabela 4

\section{Classificação dos países de acordo com Gray (1988)}

\begin{tabular}{lclc}
\hline Classificação Gray (1988) & Respostas & Classificação Gray (1988) & Respostas \\
\hline Anglo-Saxônicos & $\mathbf{9 9}$ & Germânico & $\mathbf{2 2}$ \\
\hline África do Sul & 2 & Alemanha & 3 \\
\hline Austrália & 17 & Áustria & 7 \\
\hline Canadá & 14 & Suíça & $\mathbf{1 1}$ \\
\hline EUA & 31 & Nórdicos & 3 \\
\hline Irlanda & 2 & Dinamarca & 1 \\
\hline Nova Zelândia & 3 & Escandinávia & 2 \\
\hline Reino Unido & 30 & Holanda & 5 \\
\hline China & $\mathbf{6}$ & Suécia & $\mathbf{3 4}$ \\
\hline China & 6 & Latinos & 3 \\
\hline Países de Médio Oriente & $\mathbf{4}$ & Bélgica & 1 \\
\hline Dubai & 1 & Brasil & 2 \\
\hline Irã & 1 & Chile & 12 \\
\hline Israel & 1 & Espanha & 13 \\
\hline Paquistão & 1 & França & 1 \\
\hline Asiáticos colonizados & Itália & 1 \\
\hline Índia & $\mathbf{8}$ & Malta & 1 \\
\hline Singapura & 7 & México & $\mathbf{1 5}$ \\
\hline Asiáticos pouco desenvolvidos & $\mathbf{1}$ & Japão & 15 \\
\hline Coreia & 1 & Japão & 3 \\
\hline
\end{tabular}

É possível verificar pela Tabela 4 que os países mais participativos nesse processo foram os EUA e o Reino Unido (países anglo-saxônicos), estando em conformidade com os estudos de Chatham, Larson e Vietze (2010) e Huian (2013).

Para analisar as hipóteses acima apresentadas, foi utilizado o teste não paramétrico do Qui-quadrado com recurso ao software estatístico Predictive Analytics SoftWare (PASW), tendo sido definido um nível de significância (ou p-value) de 5\%, utilizado, designadamente, no trabalho desenvolvido por Carmo et al. (2011). Como um teste não paramétrico aplicável a duas amostras independentes, a sua principal vantagem consiste na utilização em amostras cuja normalidade não se verifica (Hill \& Hill: 2008). A escolha do método está relacionada com as escalas utilizadas neste estudo, uma vez que o teste do Qui-quadrado é mais adequado a escalas do tipo nominal e em análises de distribuição de frequências. Esse teste analisa se dois ou mais grupos independentes diferem relativamente a uma determinada característica, isto é, se a frequência com que os elementos da amostra se repartem pelas classes de uma variável qualitativa, é ou não, aleatória. O Qui-quadrado mede a probabilidade de as diferenças encontradas nos dois grupos da amostra serem devido ao acaso (Maroco, 2003).

O próximo ponto dedica-se à apresentação dos resultados obtidos, tendo em conta as linhas metodológicas anteriormente apresentadas. 


\section{Resultados}

O presente artigo propõe-se a investigar as diferenças em termos da cultura, tendo em conta os quatro valores contabilísticos identificados por Gray (1988), nomeadamente, o conservardorismo, o profissionalismo, a uniformidade e o secretismo, a partir da participação dos países respondentes nos processos de emissão/alteração de normas do International Accounting Standard Board (Iasb). Para o efeito, foram recolhidas e posteriormente analisadas as questões postas à discussão por parte do Iasb aos preparadores e utilizadores da informação financeira e organismos normalizadores relativamente à primeira parte da primeira fase do projeto de substituição da International Accounting Standard (IAS) 39 - Instrumentos Financeiros: Classificação e mensuração pela International Financial Reporting Standard (IFRS) 9.

A Tabela 5 identifica os resultados obtidos para as questões relacionadas com o conservadorismo, ou seja, com a H1.1.

Tabela 5

Resultados para a H1.1

\begin{tabular}{|c|c|c|c|c|c|c|c|c|c|c|c|}
\hline & \multicolumn{5}{|c|}{ Países com (-) Conservadorismo } & \multicolumn{5}{|c|}{ Países com (+) Conservadorismo } & \multirow{2}{*}{$\begin{array}{l}\text { Pearson } \\
\text { Chi-Square }\end{array}$} \\
\hline & 0 & $\%$ & 1 & $\%$ & Total & 0 & $\%$ & 1 & $\%$ & Total & \\
\hline Questão 1.1 & 17 & $17 \%$ & 81 & $83 \%$ & 98 & 0 & $0 \%$ & 60 & $100 \%$ & 60 & 0,001 \\
\hline Questão 3.1 & 43 & $48 \%$ & 47 & $52 \%$ & 90 & 8 & $13 \%$ & 52 & $87 \%$ & 60 & 0,000 \\
\hline Questão 4.1 & 42 & $48 \%$ & 46 & $52 \%$ & 88 & 8 & $13 \%$ & 52 & $87 \%$ & 60 & 0,001 \\
\hline Questão 4.2 & 16 & $22 \%$ & 56 & $78 \%$ & 72 & 4 & $7 \%$ & 52 & $93 \%$ & 56 & 0,020 \\
\hline Questão 6.1 & 51 & $63 \%$ & 30 & $37 \%$ & 81 & 27 & $49 \%$ & 28 & $51 \%$ & 55 & 0,108 \\
\hline Questão 8.1 & 43 & $49 \%$ & 45 & $51 \%$ & 88 & 7 & $10 \%$ & 66 & $90 \%$ & 73 & 0,000 \\
\hline Questão 9.1 & 27 & $40 \%$ & 41 & $60 \%$ & 68 & 3 & $5 \%$ & 60 & $95 \%$ & 63 & 0,000 \\
\hline Questão 10.1 & 29 & $32 \%$ & 62 & $68 \%$ & 91 & 14 & $20 \%$ & 57 & $80 \%$ & 71 & 0,082 \\
\hline Questão 10.2 & 63 & $69 \%$ & 28 & $31 \%$ & 91 & 64 & $86 \%$ & 10 & $14 \%$ & 74 & 0,009 \\
\hline Questão 14.1 & 8 & $11 \%$ & 63 & $89 \%$ & 71 & 1 & $2 \%$ & 53 & $98 \%$ & 54 & 0,044 \\
\hline Questão 15.1 & 10 & $14 \%$ & 61 & $86 \%$ & 71 & 0 & $0 \%$ & 53 & $100 \%$ & 53 & 0,004 \\
\hline Questão 15.2 & 9 & $13 \%$ & 61 & $87 \%$ & 70 & 0 & $0 \%$ & 51 & $100 \%$ & 51 & 0,008 \\
\hline
\end{tabular}

É observável na tabela anterior que existem diferenças significativas para todas as questões, com exceção da 6.1 e da 10.1, uma vez que o indicador Pearson Chi-Square é inferior ao nível de significância adotado neste estudo (5\%).

Os resultados obtidos para a questão 10.2 indicam que $86 \%$ das respostas provenientes de países mais conservadores são contrários à classificação proposta, uma vez que consideram a mensuração de dividendos de investimentos em capital próprio em resultados do exercício mais útil à tomada de decisão. Por outro lado, $69 \%$ das respostas provenientes de países classificados como mais otimistas apresentam-se mais conservadoras. Assim, apesar de existirem diferenças significativas, tais diferenças não estão relacionadas com o valor do conservadorismo, uma vez que os referidos resultados contrariam a hipótese definida.

Conclui-se que a H1.1 é confirmada em todas as questões relacionadas com o conservadorismo, à exceção das questões 6.1; 10.1 e 10.2. Ressalve-se, no entanto, que a confirmação da referida hipótese encontra-se mais dependente dos países conservadores, uma vez que as respostas obtidas de países menos conservadores apresentam, na maioria dos casos, frequências semelhantes entre as respostas, contrariando, em alguns casos, a H1.1. 
A Tabela 6 apresenta os resultados obtidos para as questões relacionadas com o profissionalismo, ou seja, a H1.2.

Tabela 6

Resultados para $\mathrm{H} 1.2$

\begin{tabular}{|c|c|c|c|c|c|c|c|c|c|c|c|}
\hline & \multicolumn{5}{|c|}{ Países com (-) Profissionalismo } & \multicolumn{5}{|c|}{ Países com (+) Profissionalismo } & \multirow{2}{*}{$\begin{array}{l}\text { Pearson } \\
\text { Chi-Square }\end{array}$} \\
\hline & 0 & $\%$ & 1 & $\%$ & Total & 0 & $\%$ & 1 & $\%$ & Total & \\
\hline Questão 2.1 & 86 & $93 \%$ & 6 & $7 \%$ & 92 & 57 & $92 \%$ & 5 & $8 \%$ & 62 & 0,715 \\
\hline
\end{tabular}

É observável, assim, que tanto nos países com maiores índices de profissionalismo como nos menores para o mesmo valor contabilístico, as respostas referem que a ED não contém orientações suficientes, o que indicia menores níveis de profissionalismo. Do total de 154 respostas a esta questão, apenas 11 consideraram que a ED propõe orientações suficientes, o que poderá indicar uma eventual falta de clareza nas orientações relacionadas com as caraterísticas básicas de empréstimo e o rendimento contratual.

Assim, os resultados obtidos para H1.2 evidenciam que não existem diferenças significativas entre as respostas obtidas por parte dos países relativamente ao valor do profissionalismo.

A Tabela 7 enfatiza os resultados relacionados com o valor contabilístico da uniformidade, ou seja, a H1.3.

Tabela 7

Resultados obtidos para H1.3

\begin{tabular}{|c|c|c|c|c|c|c|c|c|c|c|c|}
\hline & \multicolumn{5}{|c|}{ Países com (-) Uniformidade } & \multicolumn{5}{|c|}{ Países com (+) Uniformidade } & \multirow{2}{*}{$\begin{array}{c}\text { Pearson } \\
\text { Chi-Square }\end{array}$} \\
\hline & 0 & $\%$ & 1 & $\%$ & Total & 0 & $\%$ & 1 & $\%$ & Total & \\
\hline Questão 5.1 & 1 & $1 \%$ & 87 & $99 \%$ & 88 & 4 & $7 \%$ & 57 & $93 \%$ & 61 & 0,071 \\
\hline Questão 7.1 & 62 & $70 \%$ & 27 & $30 \%$ & 89 & 56 & $88 \%$ & 8 & $13 \%$ & 64 & 0,010 \\
\hline Questão 11.1 & 16 & $36 \%$ & 29 & $64 \%$ & 45 & 21 & $53 \%$ & 19 & $48 \%$ & 40 & 0,116 \\
\hline Questão 13.1 & 36 & $47 \%$ & 40 & $53 \%$ & 76 & 34 & $65 \%$ & 18 & $35 \%$ & 52 & 0,044 \\
\hline
\end{tabular}

Na Tabela 7, é possível verificar que apenas nas questões 7.1 e 13.1 foi possível encontrar diferenças significativas entre as respostas obtidas, tendo em conta a classificação do país respondente quanto à uniformidade.

Os resultados obtidos para a questão 7.1 demonstram que em ambas as culturas (mais uniformes e menos uniformes) há uma preferência pela possibilidade de reclassificação de instrumentos financeiros. No entanto, essa diferença apresenta-se mais acentuada no contexto dos países cuja cultura contabilística é mais uniforme ( $88 \%$ contra $70 \%$ nos países com menores índices de uniformidade). Assim, e apesar de serem encontradas diferenças significativas entre as respostas obtidas por parte dos países para esta questão, tais diferenças apresentam-se contrárias à hipótese.

Por último, apesar de existirem diferenças significativas entre as respostas obtidas para a questão 13.1, tais diferenças contrariam a H1.3, uma vez que $65 \%$ dos países com cultura mais uniforme responderam que não concordam com a aplicação retrospectiva da norma, ao passo que 53\% dos países com cultura mais flexível concordam com o referido procedimento. Tal resultado pode ser explicado pelo fato de, em muitos casos, esta posição dever-se essencialmente ao custo da sua aplicação, em detrimento da qualidade da informação financeira.

Assim, conclui-se que a H1.3 não se confirma em nenhuma das questões associadas à uniformidade, uma vez que não existem diferenças significativas entre as respostas obtidas que sejam motivadas pela cultura. 
A Tabela 8 apresenta os resultados obtidos relativamente ao valor contabilístico de Gray (1988) do secretismo.

Tabela 8

Resultados obtidos para H1.4

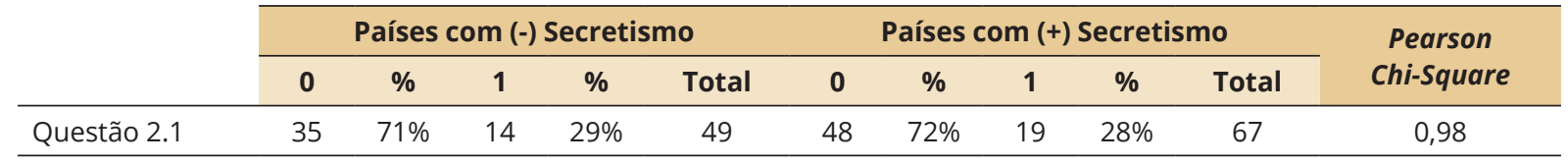

Verifica-se, pela análise da Tabela 8 , que não existem diferenças significativas entre as respostas obtidas por parte dos países respondentes relacionadas com o secretismo. A distribuição das respostas obtidas por país de origem é muito semelhante, o que indica que não há influência de valores culturais.

Assim, os resultados demonstram que, na maioria dos casos, os respondentes não concordam com as divulgações adicionais propostas pela IFRS para as empresas que aplicam a norma antes da data efetiva. Também aqui muitas respostas associam a não concordância aos custos elevados que as divulgações adicionais trariam às empresas, pelo que os resultados podem indicar a preferência por custos reduzidos.

O próximo ponto apresenta, por fim, as principais conclusões, limitações e perspectivas futuras identificadas para o desenvolvimento futuro deste estudo.

\section{Conclusões}

Os resultados obtidos para o valor do conservadorismo demonstram, em linha com outros estudos analisados, tais como MacArthur (1996), Doupnik e Riccio (2006) e Albuquerque e Almeida (2009), que a cultura pode apresentar-se como um fator que afeta as práticas contabilísticas dos respondentes, ao verificar-se a existência de diferenças em torno das respostas obtidas, motivadas pela cultura, no contexto das respostas obtidas por parte dos países. Conclui-se, assim, que os países classificados como mais conservadores têm preferência por práticas de mensuração mais conservadoras, baseadas designadamente no custo ou no custo amortizado, em detrimento de critérios de mensuração baseados no justo valor.

Verifica-se, no caso da H1.1, que os países menos conservadores apresentam respostas mais distintas entre si, enquanto os mais conservadores são mais homogêneos nas opiniões emitidas, o que significa que a confirmação desta hipótese está mais dependente dos países com elevados níveis de conservadorismo.

Relativamente aos restantes valores contabilísticos, nomeadamente, o profissionalismo, a uniformidade e o secretismo, não foram encontradas diferenças significativas entre as respostas obtidas por parte dos países respondentes, pelo que não se confirmam as H1.2, H1.3 e H1.4.

No contexto do profissionalismo, é observável que a questão em análise obteve uma posição quase unânime por parte dos respondentes - apenas 11 dos 154 respondentes a esta questão (cerca de 7\%) responderam de acordo com um maior índice de profissionalismo, o que pode indicar que são, efetivamente, necessárias orientações adicionais no que toca à classificação e mensuração de instrumentos financeiros.

Relativamente ao secretismo, verifica-se que as respostas apresentadas associam a sua posição de oposição às divulgações adicionais aos custos elevados que estas exigem.

No que toca à uniformidade, verifica-se, nos casos em que existem diferenças significativas por parte dos países respondentes, que tais respostas apresentam-se contrárias à hipótese estabelecida, ou seja, as respostas que indicam maiores índices de uniformidade são provenientes de países com menores índices do mesmo valor contabilístico. 
A principal limitação deste trabalho prende-se com o método de pesquisa utilizado (a análise de conteúdo), uma vez que este método introduz alguma subjetividade ao trabalho, especialmente nos casos em que as respostas obtidas são pouco claras, dificultando a interpretação.

Adicionalmente, para alguns valores contabilísticos, como o secretismo e o profissionalismo, existe apenas uma questão-alvo de análise, o que pode estar na base das conclusões identificadas no ponto anterior, isto é, não validação da hipótese proposta para os referidos valores.

Para futuras investigações, sugere-se a realização do estudo proposto às restantes fases de substituição da IAS 39 pela IFRS 9, bem como o alargamento deste mesmo estudo a outras normas que se encontram igualmente em processo de substituição, abarcando assim outros temas distintos dos instrumentos financeiros.

O estudo das diferenças internacionais no âmbito da Contabilidade e dos diferentes interesses dos grupos de stakeholders da informação financeira é importante para os países e organismos envolvidos no processo de harmonização contabilística internacional. Assim, pretende-se que os resultados obtidos neste estudo prestem o suporte necessário à tomada de decisões por parte dos organismos emissores de normas internacionais, bem como pelos responsáveis nacionais pela subscrição das referidas normas.

Perceber os impactos e a incidência dos conceitos relacionados com a prática contabilística, com base no julgamento profissional, contribui para que os objetivos que estão por trás do processo de harmonização, designadamente, a efetiva comparabilidade do relato financeiro ao nível internacional, sejam mais facilmente atingidos.

\section{Referências}

Abdolmohammadi, M. \& Sarens, G. (2009). Cultural dimension as an explanatory variable in use and compliance with internal auditing standards in nineteen countries. Anais do Annual meeting of the American Accounting Association. Nova Iorque. Recuperado em 20 novembro, 2013 de http://papers.ssrn.com/sol3/papers.cfm?abstract_id=1326071

Albuquerque, F. \& Almeida, M. (2009). A cultura, os valores contabilísticos e o julgamento profissional dos preparadores portugueses. APOTEC: Prémio Luiz Chaves de Almeida.

Alves, M. \& Antunes, E. (2010). A implementação das Normas Internacionais de Contabilidade na Europa - um estudo comparativo. Covilhã: Universidade da Beira Interior. Working Paper. Recuperado em 20 novembro, 2013 de http://www.dge.ubi.pt/investigacao/TDiscussao/TD10_2010.pdf.

Amat, O., Blake, J., Wraith, P. \& Oliveras, E. (2010). Dimensions of national culture and the accounting environment - the spanish case. Universitat Pompeu Fabra. Working Paper. Recuperado em 20 novembro, $2013 \mathrm{de}$ http://papers.ssrn.com/sol3/papers.cfm?abstract_id=189430

Baskerville, R. (2003). Hofstede never studied culture. Accounting, Organizations and Society. 28(1), pp.1-14.

Baydoun, N. \& Willett, R. (1995). Cultural relevance of western accounting systems to developing countries. Abacus. 31(1), pp. 67-92. DOI: 10.1111/j.1467-6281.1995.tb00355.x

Carmo, C., Ribeiro, A. \& Carvalho, L. (2011). Convergência de fato ou de direito? A influência do sistema jurídico na aceitação das normas internacionais para pequenas e médias empresas. Revista Contabilidade Financeira. 22(57), pp.242-262. DOI: http://dx.doi.org/10.1590/S1519-70772011000300002

Chanchani, S. \& Willett, R. (2004). An empirical assessment of Gray's accounting value constructs. The international Journal of Accounting. 39(2), pp.125-15. DOI: 10.1016/j.intacc.2004.02.003

Chatham, M., Larson, R. \& Vietze, A. (2010). Issues affecting the development of an international accounting standard on financial instruments. Advances in Accounting. 26(1), pp. 97-107. DOI: 10.1016/j. adiac.2010.03.002 
Chow, L., Chau, G. \& Gray, S. (1995). Accounting reforms in china: cultural constraints on implementation and development. Accounting and Business Research. 26(1), pp. 29-49. DOI: 10.1080/00014788.1995.9729497

Ding, Y., Jeanjean, T. \& Stolowy, H. (2005). Why do national GAAP differ from IAS? The role of culture. The international Journal of Accounting. 40(4), pp. 325-340. doi:10.1016/j.intacc.2005.09.004

Doupnik, T. \& Salter, S. (1995). External environment, culture, and accounting practices: a preliminary test of a general model of international accounting development. The International Journal of Accounting. 30(3), pp.189-207.

Doupnik, T. \& Riccio, S. (2006). The influence of conservatism and secrecy on the interpretation of verbal probability expressions in the Anglo and Latin cultural areas. The International Journal of Accounting. 41(3), pp.237-261. doi:10.1016/j.intacc.2006.07.005

Elnathan, D. \& Krilich, S. (1992). Accounting harmonization in regional trade blocs. A trend for the 21 st century. Business Forum. 17(1), pp.47-50.

Finch, N. (2006). Towards an Understanding of Cultural Influence on the International Practice of Accounting. Journal of International Business and Cultural Studies. 2(1), pp. 1-6. DOI: http://hdl.handle.net/1959.14/72074

Gaver, J. \& Pottier, S. (2005). The role of holding company financial information in the insurer- rating process: evidence from the property- liability industry. The Journal of Risk and Insurance. 72(1), pp.77103. DOI: 10.1111/j.0022-4367.2005.00117.x

Göx, R. \& Wagenhofer, A. (2009). Optimal impairment rules. Journal of Accounting and Economics. 48(1), pp. 2-16. doi:10.1016/j.jacceco.2009.04.004

Gray, S. (1988). Towards a theory of cultural influence on the development of accounting systems internationally. Abacus. 24(1), pp. 1-15. DOI: 10.1111/j.1467-6281.1988.tb00200.x

Haller, A. \& Walton, P. (2003). International accounting (2a Ed.). Londres: Thomson Learning.

Hill, M. \& Hill, A. (2008). Investigação por questionário. (2a Ed.). Lisboa: Edições Sílabo,

Hofstede, G. (1980). Culture's consequences: international differences in work-related values. Londres; Sage Publications.

Hope, O. (2003). Firm-level disclosures and the relative roles of culture and legal origin. Journal of International Financial Management and Accounting. 14(3), pp. 218-248. DOI: 10.1111/1467-646X.00097

Hope, O., Kang, T., Thomas, W. \& Yoo, Y. (2008). Culture and auditor choice: a test of the secrecy hypothesis. Journal of Accounting and Public Policy. 27(5). pp. 357-373. doi:10.1016/j.jaccpubpol.2008.07.003

Huian, M. (2013). Stakeholder's participation in the development of the new accounting rules regarding the impairment of financial assets. Business Management Dynamics. 2(9), pp. 23-35.

Jaggi, B. \& Low, P. (2000). Impact of culture, market forces, and legal system on financial disclosures. The International Journal of Accounting. 35(4), pp.495-519. DOI: 10.1016/S0020-7063(00)00076-5.

Jorissen, A., Lybaert, N. \& Van de Poel, K. (2006). Lobbing towards a global standard setter - do national characteristics matter? An analysis of the comment letters written to the IASB. In International Accounting: standards, regulations and financial reporting. Netherlands: Elsevier. pp. 1-40

La Porta, R., Silanes, F., Shleifer, A. \& Vishny, R. (1996). Law and finance. NBER Working Paper. 5661. National Bureau of Economic Research. Recuperado em 20 novembro, 2013 de http://www.nber. org/papers/w5661 
MacArthur, J. (1996). An Investigation into the influence of cultural factors in the international lobbying of the International Accounting Standards Committee: the case of E32, comparability of financial statements. The International Journal of Accounting. 31(2), pp. 13-237. DOI: http://dx.doi.org/10.1016/ S0020-7063(96)90005-9

Marôco, J. (2003). Análise estatística com utilização do SPSS. (2ª Ed.). Lisboa: Edições Sílabo

Nobes, C. (1998). Towards a general model of the reasons for international differences in financial reporting. Abacus. 34(2), pp.162-187. DOI: 10.1111/1467-6281.00028

Perera, H., Cummings, L. \& Chua, F. (2012). Cultural relativity of accounting professionalism: evidence from New Zealand and Samoa. Advances in Accounting, incorporating Advances in International Accounting. 28(1), pp. 138-146. DOI: 10.1016/j.adiac.2012.03.006

Radebaugh, L. \& Gray, S. (1996). International Accounting and multionational enterprises (16 $\left.{ }^{\mathrm{a}} \mathrm{Ed}.\right)$. New Jersey: John Wiley \& Sons, Inc.

Regulamento (CE) no 1606/2002, de 19 de julho. (jul 2002) Bruxelas: Jornal Oficial da União Europeia L 243 de 2002-11-11. [Em linha]. Rercuperado em 26 junho, 2013 de http://eur-lex.europa.eu/LexUriServ/LexUriServ.do?uri=OJ:L:2002:243:0001:000:pt:PDF;.

Roberts, C. e Salter, S. (1999). Attitudes towards uniform accounting: cultural or economic phenomena? Journal of International Financial Management \& Accounting. 10(2), pp. 121-142. DOI: 10.1111/1467646X.00047

Schwartz, S. (1994). Are there universal aspects in the structure and contents of human values? Journal of Social Issues. 50(4), pp.19-45. DOI: 10.1111/j.1540-4560.1994.tb01196.x.

Tsakumis, G. (2007). The influence of culture on accountants' application of financial reporting rules. Abacus. 43(1), pp. 27-48. DOI: http://dx.doi.org/10.1111/j.1467-6281.2007.00216.x

Yen, A; Hirst, D. e Hopkins, P. (2007). A Content Analysis of the Comprehensive Income Exposure Draft Comment Letters. Research in Accounting Regulation. 19, pp. 53-79. doi:10.1016/S10520457(06)19003-7

Wang, H. (2012). The decision usefulness of fair value accounting in the debt market. Tese de doutoramento, Quebec: The John Molson School of Business.

Weber, R. (1990). Basic content analysis (2a Ed.) Newbury Park: Sage. 